\title{
A Pilot Study Re Behavioral Root of Cultural-Historical Development: A Neo-Darwinian Stance
}

\author{
Saeed Shoja Shafti* \\ Department of Psychiatry, University of Social Welfare and Rehabilitation Sciences (USWR), Tehran, Iran \\ *Corresponding author: Saeed Shoja Shafti, Department of Psychiatry, University of Social Welfare and Rehabilitation Sciences \\ (USWR), Tehran, Iran
}

\begin{abstract}
Introduction: No doubt, evolutionary psychologists are trying to enlighten personality and individual differences by way of various theories. But, essentially and from an evolutionary point of view, a few studies exist regarding personality characters. In the present assessment, relationship between obsessive-compulsive personality traits and achievement of people had been assessed.
\end{abstract}

Method and Material: Four hundreds relatives, who had been elected randomly, have been questioned by means of a self-reply inquiry form as regards the existence of obsessive-compulsive personality traits, in their highest and lowest successful offspring. Data were analyzed by $\mathrm{z}$ test for comparison of proportions.

Results: Except for 'stubbornness', all of traits were meaningfully more prevalent among the highest successful kids, in comparison with the lowest successful children. "Perfectionism' was the most prevalent character among successful group, tagged along by 'Rigidity regarding Morality and ethics', 'Orderliness and devoting to details' and 'Devoting to work and avoiding Leisure'. 'Obligating others to submit his or her style of behavior', 'collecting objects and money' and 'parsimoniousness', were the least prevalent qualities.

Conclusion: Obsessive-compulsive traits, at a sensible level, seem to be one of the main interactive dynamics that may help people with regard to achievement of personal and social triumphs.

Keywords: Obsessive-compulsive personality trait; Evolutionary psychology; Evolutionary psychiatry

\section{Introduction}

According to DSM-5, 'obsessive-compulsive personality disorder' is one of the most prevalent personality syndromes in the population, with likely frequency ranging from $2.1 \%$ to $7.9 \%$ [1]. In systematic studies, 'obsessive-compulsive personality disorder' appears to be diagnosed about twice as often among men. The necessary feature of 'obsessive-compulsive personality disorder' is perfectionism, preoccupation with orderliness, and mental and interpersonal control, at the expense of openness, flexibility and productivity. This configuration begins by early adulthood and is existent in a variety of circumstances. Personalities with such kind of disorder attempt to maintain a sense of control through painstaking attention to rules, procedures, lists, trivial details, or schedules to the extent that the main point of the activity is missing (Criterion 1) [1]. They are disproportionately watchful and susceptible to repetition, paying unusual attention to detail and repeatedly checking for possible faults. They may become so involved in making every detail of a project completely perfect that the mission is never ended (Criterion 2) [1]. Such individuals show extreme devoutness to work and productivity to the exclusion of leisureliness and friendships (Criterion 3) [1].

When they do take time for vacations or holidays, they are very uncomfortable unless they have taken along something to work on, so they do not 'waste time.' The emphasis is on faultless enactment. They may be extremely conscientious, trustworthy, and inflexible about matters of ethics, moral code, or principles (Criterion 4) [1]. They may also be unpityingly self-critical about their own faults or slips. Persons with this syndrome are rigidly respectful to authority and instructions and insist on quite precise obedience, with no 
rule bending for moderating situations. The aforesaid qualities should not be accounted for by the individual's religious or cultural credentials. Personalities with this disorder may be unable to throw away worn-out or useless stuffs, even when they have no emotional value (Criterion 5). They are unwilling to delegate tasks or to work with others (Criterion 6) [1]. Also, such persons may be parsimonious and ungenerous and maintain a standard of living far below what they can pay for, considering that expenditure must be tightly controlled to provide for future misfortunes (Criterion 7) [1]. This disorder is characterized by rigidity and stubbornness (Criterion 8) and unwilling to consider changes.

They may be preoccupied with rationality and intelligence, and intolerant of sentimental behavior in others. They often have difficulty conveying affectionate feelings, rarely paying compliments. Many of the features of this disorder is similar to "type A" personality characteristics (e.g., preoccupation with work, competitiveness and time urgency), and these features may be present in people at risk for myocardial infarction [1]. For over 80 years, astute clinical observers, including the eminent British psychiatrist Aubrey Lewis, have described two types of obsessivecompulsive personality [2]. Lewis noted, 'one [was] obstinate, morose, irritable, the other vacillating, uncertain of himself, submissive' [2]. Features of the second type were included in DSMIII, with the addition of 'indecisiveness' and 'restricted expression of affection' [3]. These features were retained in DSM-III-R but dropped in DSM-IV. 'Indecisiveness' seems to have been dropped for the reason that some studies revealed low sensitivity and specificity, and it was comparatively common in patients with other personality disorders including 'paranoid', 'schizotypal', 'avoidant' and 'dependent' [4].

However, an evaluation using stepwise logistic regression modeling found only modest support for this verdict [5]. The cause of OCPD is thought to encompass a combination of genetic and environmental factors [6]. Under the genetic theory, people with a form of the DRD3 gene will probably develop OCPD and depression, principally if they are male [7]. But genetic concomitants may lie latent until activated by happenings in the lives of those who are liable to OCPD. These events could consist of parenting styles that are over-involved and/or excessively protecting, as well as trauma faced during babyhood. Traumas that could lead to OCPD include emotional, physical or sexual abuse, or other psychological traumas. Under the environmental philosophy, OCPD is a learned behavior [7]. Also, little is known about the etiologic connection between obsessive-compulsive (OC) symptoms and traits of OCPD [8]. Some theoreticians have proposed that OCPD is one of several disorders falling within an OC spectrum. This infers that OC personality traits and symptoms should have etiologic dynamics in common, and this should not be merely because symptoms and traits are both shaped by general etiological effects. So, to investigate these issues, in a study a community sample of 307 pairs of monozygotic and dizygotic adult twins provided scores on six types of OC-related symptoms, two markers of negative emotionality, and a measure of OC personality traits.

In the end, OC symptoms and traits were etiologically related, mostly because they are shaped by the same general genetic factor that influenced negative emotionality [8]. Presently, no single specific cause of OCPD has been identified. Since the early days of Freudian psychoanalysis, however, faulty parenting has been viewed as a major factor in the development of personality disorders. Current studies have tended to support the importance of early life experiences, finding that healthy emotional development largely depends on two important variables: parental warmth and appropriate responsiveness to the child's needs [9]. When these qualities are present, the child feels secure and appropriately valued. By contrast, many people with personality disorders did not have parents who were emotionally warm toward them. Patients with OCPD often recall their parents as being emotionally withholding and either over-protective or over-controlling. One researcher has noted that people with OCPD appear to have been punished by their parents for every transgression of a rule, no matter how minor, and rewarded for almost nothing. As a result, the child is unable to safely develop or express a sense of joy, spontaneity, or independent thought, and begins to develop the symptoms of OCPD as a strategy for avoiding punishment.

Children with this type of upbringing are also likely to choke down the anger they feel toward their parents; they may be outwardly obedient and polite to authority figures, but at the same time treat younger children or those they regard as their inferiors harshly. While genetic contributions to OCPD have not been yet well documented, cultural influences may, however, play a part in the development of OCPD [10]. That is, cultures that are highly controlling and rule-bound may encourage child-rearing rehearses that contribute to the development of OCPD. On the other hand, simply because a culture is comparatively strict or has a strong work ethic does not mean it is necessarily detrimental. In Japanese societies, for example, excessive devotion to work, restricted emotional expression, and ethical scrupulosity are highly valued features that are rewarded within that culture. So, OCPD is not diagnosed in persons who are simply behaving in accordance with cultural or exterior expectations. Nevertheless, in spite of all the aforementioned statements, and from an evolutionary or sociobiological standpoint in the realm of social Darwinism, amongst a variety of personality characters, obsessive-compulsive traits generally seem to be suitable for assuring human achievement.

Having faith in orderliness and concern with details, devoting to work, perfectionism, parsimoniousness, conscientiousness, putting force on others for obeying them and insisting on well-organized decisions, all are in contrast with the chaotic life style of borderline persons, exploitative style of narcissistic individuals, social disregard of sociopaths, guardedness of paranoid people, social 
avoidance of schizoid and schizotypal persons, isolation of avoidant individuals, passivity of dependent people, and attention seeking efforts of histrionic persons. On the other hand, while evolutionary psychologists agree that evolution is pertinent to all psychological mechanisms, and different theories are trying to explain personality variances and individual alterations, in comparison with other related fields, there has been very little investigation done on personality from an evolutionary perspective. So, for evaluation of such a conjecture, a pilot appraisal had been accomplished to measure that: is there basically any apparent affiliation between obsessive-compulsive traits and social progression of persons?

\section{Method and Material}

Four hundreds relatives, who have been elected randomly among normal patrons of a general hospital, during a six months period, have been questioned with reference to the existence of obsessive-compulsive personality characters, in their highest and lowest successful children, based on the inclusion criteria of Diagnostic and Statistical Manual of Mental Disorders, 5th edition [1]. In this regard, success was demarcated approximately as the "greatest attainable accomplishment" in personal, social, occupational and educational aspects of life, according to 'their own values and standpoints'. Fathers, mothers or both had been asked by a self-reply inquiry form, which involved the complete obsessive-compulsive traits, itemized with distinct checkmark columns, for their highest and lowest successful children. Moreover, it had been highlighted for responders that such characterization of "success" could only be admissible, when there was no any exterior or unavoidable factor accountable for the triumph or defeat. The families with fewer than two children or youngsters less than fourteen years old were omitted from the assessment. If there were more than two children beyond fourteen years old, the parents were requested to pick among them the highest and lowest successful ones, based on their own judgment and individual sociocultural principles.

\section{Statistical Analysis}

While data were analyzed by $\mathrm{z}$ test for comparison of proportions, significance was demarcated as a $\mathrm{p}$ value equal to or less than 0.05. MedCalc Statistical Software version 15.2 was used as statistical software instrument for analysis.

\section{Results}

Demographic features of the participants have been shown in Table 1. Eight hundreds offspring, including 393 male and 403 female children, had been probed in the present assessment $(\mathrm{z}=$ $-0.70, \mathrm{p}<0.48,95 \% \mathrm{CI}=-0.06,0.03$ ) (Figure 1 ). In this regard, $\mathrm{z}$ test for 'comparison of proportions' did not display any gender-based significance between highest $(\mathrm{z}=0.56, \mathrm{p}<=0.57$, CI 95\%=- 0.04 , $0.08)$ and lowest successful offspring $(\mathrm{z}=-1.55, \mathrm{p}<0.11, \mathrm{CI} 95 \&=$ - 0.12, 0.01). In keeping with the conclusions, and in comparison, with the lowest successful children, all of the obsessive-compulsive traits, except than 'stubbornness', were meaningfully more prevalent among the highest successful kids (Table 2) and (Figure 2). 'Perfectionism' was the most prevalent peculiarity among successful group of children, followed by 'Rigidity regarding morality and ethics', 'Orderliness and devoting to details' and 'Devoting to work and avoiding leisure'. By the way, 'Obligating others to submit his or her style of behavior,', Collecting objects and money' and finally 'Parsimoniousness', too, were the least widespread characters.

Table 1: Demographic characteristics of participants.

\begin{tabular}{|cccc|}
\hline $\begin{array}{c}\text { Successful } \\
\text { Children }\end{array}$ & Male & Female & Total \\
\hline Highest & 204 & 196 & 400 \\
Lowest & 189 & 211 & 400 \\
Total & 393 & 407 & 800 \\
\hline
\end{tabular}

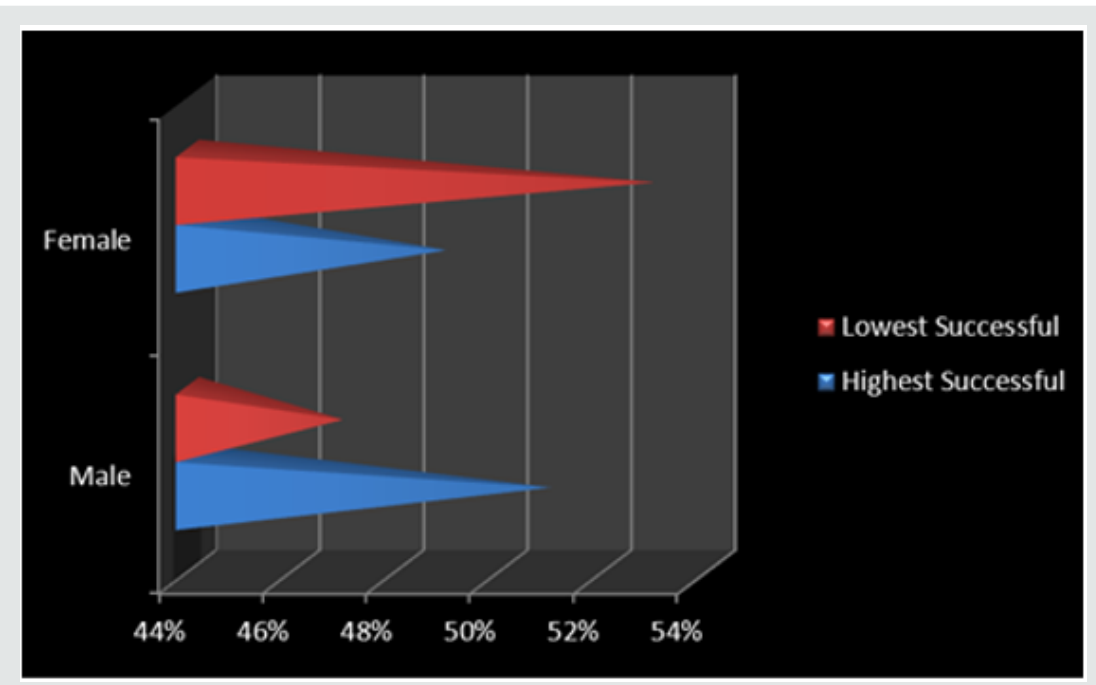

Figure 1: Percentage of highest and lowest successful participants. 


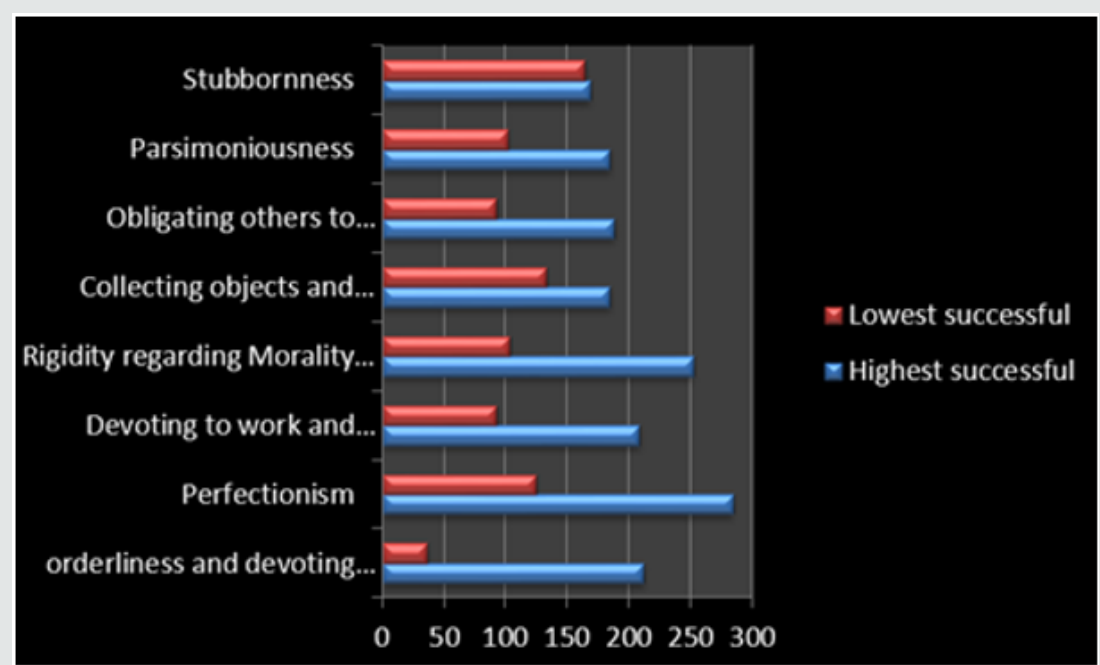

Figure 2: Frequency of obsessive-compulsive traits among participants.

Table 2: Prevalence of obsessive-compulsive traits among participants.

\begin{tabular}{|c|c|c|c|c|c|}
\hline Character & $\begin{array}{l}\text { Number of Highest } \\
\text { successful }\end{array}$ & $\begin{array}{c}\text { Number of Lowest } \\
\text { successful }\end{array}$ & $\mathbf{z}$ & p-value & $95 \% \mathrm{CI}$ \\
\hline Orderliness and devoting to details & 212 & 36 & 13.45 & 0 & $0.37,0.50$ \\
\hline Perfectionism & 284 & 124 & 11.31 & 0 & $0.33,0.46$ \\
\hline Devoting to work and avoiding leisure & 208 & 92 & 8.47 & 0 & $0.22,0.35$ \\
\hline Rigidity regarding Morality and ethics & 252 & 103 & 10.82 & 0 & $0.31,0.44$ \\
\hline Collecting objects and money & 184 & 132 & 3.76 & 0 & $0.06,0.19$ \\
\hline $\begin{array}{l}\text { Obligating others to submit his or her style of } \\
\text { behavior }\end{array}$ & 188 & 92 & 7.11 & 0 & $0.17,0.30$ \\
\hline Parsimoniousness & 184 & 101 & 6.2 & 0 & $0.14,0.27$ \\
\hline Stubbornness & 168 & 164 & 0.28 & 0.77 & $0.053,0.07$ \\
\hline
\end{tabular}

\section{Discussion}

Over the last years, an increasing number of studies have revealed individual variances in a specific behavioral feature over time, between the same manners across different environmental conditions, or relations between different behavioral characters. While such investigations are indispensable for providing the material that will help us to generalize the existence of behavioral or personality patterns across the world, they are limited by their descriptive nature, and it is essential to transfer from this descriptive phase of personality studies to the experimental study of the ecological relevance and fitness consequences of personality variances [11,12]. In this regard, Reichborn-Kjennerud et al. [13] has recommended against grouping obsessive personality within the anxious and fearful cluster $\mathrm{C}$ of personality disorders, for the reason that it is much more heritable and distinct from both the avoidant and dependent personalities. As Reichborn-Kjennerud et al. [13] had stated, obsessive personality is truly 'genotypically' and 'phenotypically' distinct from its two counterparts, because the avoidant personality and the dependent personality are 'related to the ... higher-order factor' of emotional dysregulation, while the obsessive personality is related to 'the lower-order trait of compulsivity'.
While nearly all etiologies assume OCPD to be an environmentally instilled syndrome, a recent evolutionary etiology, better accounting for prevalence rates and heritability estimates, ecologically explains obsessive psychology as an adaptation to northern climates with express seasonality, low population density, and low social complexity. So, the concept of 'phylogenetic inertia', the decrease in fitness arising from incongruity between past and present selective pressures, is applied by the researcher [14]. This shows that how an evolved strategy could be mistaken for a detrimental disorder by examining the misalignment between evolved obsessive psychology and modernity's demands for flexible attention, communion and collaboration, openness and complexity. Hence, it seems that OCPD, evolved in prehistory, remains adaptive in modernity and so phylogenetic inertia can only be invoked as a metaphorical heuristic. According to some scholars, OCPD is highly heritable and not ominously influenced by "common, shared-infamilies environmental factors" [15].

Truly integrating heritability estimates into a functional etiological account of obsessive character comes from an evolutionary model that understands obsessive personality to be an evolved strategy rather than a dysfunctional disorder. As a result, 'obsessive character' or 'obsessive personality' is generally 
substituted for 'Obsessive Compulsive Personality Disorder' because the latter is a smaller subset of the former. Accordingly, the terms 'obsessive character' and 'obsessive personality' are more inclusive, subsuming both clinical and non-clinical exhibitions of the pattern. In this regard and consistent with the results of a study, among two factors of OCPD, order/control (perfectionism, excessive devotion to work, over-conscientiousness, reluctance to delegate, and rigidity) and hoarding/indecision (inability to discard and indecisiveness), the hoarding/indecision factor is familial and shows modest linkage to a region on chromosome [16]. Then again, according to some scholars, OCPD was associated with the least overall functional impairment among the personality disorders $[17,18]$; OCPD is the least pathological of the personality disorders and is not associated with impaired autonomy or attachment problems as are many personality disorders, such as borderline and avoidant personality [19]; OCPD is associated with fewer comorbidities than most other personality disorders [20]; OCPD is not associated with depressed global assessment of function (GAF) [21].

Perhaps most strikingly, obsessive character is predictive of worldly success [22]. Specifically, obsessive personality was found to be positively related to "high socio-economic status, good income, and supervisory responsibilities at work, spacious living conditions and home ownership" [23]; findings which are more or less in harmony with the assumptions and conclusions of the present study. Conversely, scholars like Soeteman et al. [24] had found OCPD to impose more of an overall economic encumbrance than all other personality disorders with the single exception of borderline personality. Likewise, some others like Diaconu and Turecki had found that depressed patients exhibit more non-lethal suicidal behavior when they carry a comorbid diagnosis of OCPD. While such declarations do not correspond with the aforementioned outlooks, is should be considered that Soeteman et al. [24] and Diaconu and Turecki had used samples that were quite low functioning, and which were comprised of persons combining an assortment of psychological difficulties from a variety of categories.

Rather than representing a specific personality type, these participants most often evidenced symptoms from multiple personality disorder categories, while also were carrying axis I symptoms. Such participants were drawn exclusively from clinical populations, who were receiving a combination of outpatient treatment, partial hospitalization and inpatient care. Besides, obsessional patients should be more socially conforming than the average person and less prone to risk taking [25]. Nevertheless, evolutionary psychology should be construed to include all inquiry that takes evolution into account, rather than as a subset of evolutionary perspectives which leans solely on adaptationism. While any explanation of human behavior should be grounded in biological evolution, this does not, of course, mean that environment, culture, and context are any less important to these analyses [26]. Small sample size, lack of exact operational definition and valid measure for evaluation of personal and/or social success, limitation of research to a middle-class urban area, lack of direct observation and appraisal of the offspring and relying on parent's subjective judgment were among the weak points of this assessment. Further large practical randomized, well-designed, appraisals are necessary to evaluate the evolutionary effects of particular characters on civilization of human being.

\section{Conclusion}

Obsessive-compulsive personality traits, at a reasonable level, seem to be one of the main behavioral factors that may help the person toward attainment of personal and/or social success.

\section{Acknowledgments}

The author gratefully acknowledges dear colleagues, Akbasi S (MD), Khorshidi M (MS), for their valuable support of this study.

\section{References}

1. American Psychiatric Association (APA) (2013) Diagnostic and Statistical Manual of Mental Disorders. 5th ed. Washington, DC: American Psychiatric Association pp. 678-682.

2. Lewis A (1936) Problems of obsessional illness. Proc R Soc Med 29(4): 325-336.

3. Hummelen B, Wilberg T, Pedersen G, Karterud S (2008) The quality of the DSM-IV obsessive-compulsive personality disorder construct as a prototype category. J Nerv Ment Dis 196(6): 446-455.

4. Pfohl B, Blum N (1991) Obsessive-compulsive personality disorder: A review of available data and recommendations for DSM-IV. J Personal Disord 5(4): 363-375.

5. Nurnberg GH, Martin GA, Pollack S (1994) An empirical method to refine personality disorder classification using stepwise logistic regression modeling to develop diagnostic criteria and thresholds. Compr Psychiatry 35(6): 409-419.

6. Joyce PR, Rogers GR, Miller AL, Mulder RT, Luty SE, et al. (2003) Polymorphisms of DRD4 and DRD3 and risk of avoidant and obsessive personality traits and disorders. Psychiatry Research 119(1-2): 1-10.

7. Light KJ, Joyce PR, Luty SE, Mulder RT, Frampton CM, et al. (2006) Preliminary evidence for an association between a dopamine $D_{3}$ receptor gene variant and obsessive-compulsive personality disorder in patients with major depression. American Journal of Medical Genetics 141B(4): 409-413.

8. Taylor S, Asmundson GJ, Jang KL (2011) Etiology of obsessive-compulsive symptoms and obsessive-compulsive personality traits: Common genes, mostly different environments. Depress Anxiety 28(10): 863-869.

9. Jenike Michael (1998) Psychotherapy of Obsessive-Compulsive Personality. In Obsessive-Compulsive Personality Disorders: Practical Management ( $3^{\text {rd }}$ edn.).

10. Baer Lee (1998) Personality Disorders in Obsessive-Compulsive Disorder." In Obsessive-Compulsive Disorders: Practical Management ( $3^{\text {rd }}$ edn.).

11. Bell A M (2007) Evolutionary biology: Animal personalities. Nature 447(7144): 539-540.

12. Cote J, Dreiss A, Clobert J (2008) Social personality traits and fitness. Proc R Soc 275(1653): 2851-2858.

13. Reichborn Kjennerud T, Czajkowski N, Neale MC, Orstavik RE, Torgersen $S$ (2007). Genetic and environmental influences on dimensional representations of DSM-IV cluster C personality disorders: A populationbased multivariate twin study. Psychological Medicine 37(5): 645-653. 
14. Steven C Hertler (2015) Obsessive Compulsive Personality Disorder as an Adaptive Anachronism: The Operation of Phylogenetic Inertia Upon Obsessive Populations in Western Modernity. Psihologijske Teme 24(2): 207-232.

15. Steven Charles Hertler (2014) A Review and Critique of ObsessiveCompulsive Personality Disorder Etiologies: Reckoning With Heritability Estimates. Europe's Journal of Psychology 10(1): 168-184.

16. Mark A Riddle, Brion S Maher, Ying Wang, Marco Grados, O Joseph Bienvenu (2016) Obsessive-compulsive personality disorder: Evidence for two dimensions. Depression and anxiety 33(2): 128-135.

17. Barber JP, Morse JQ Krakauer ID, Chittams J, Crits Christoph K (1997) Change in obsessive-compulsive and avoidant personality disorders following time-limited supportive-expressive therapy. Psychotherapy 34(2): 133-143.

18. Skodol AE, Gunderson JG, McGlashan TH, Dyck IR, Stout RL, et al. (2002) Functional impairment in patients with schizotypal, borderline, avoidant, or obsessive-compulsive personality disorder. The American Journal of Psychiatry 159(2): 276-283.

19. Aaronson CJ, Bender DS, Skodol AE, Gunderson JG (2006) Comparison of attachment styles in borderline personality disorder and obsessivecompulsive personality disorder. Psychiatric Quarterly 77(1): 69-80.

20. Mc Glashan TH, Grilo CM, Skodol AE, Gunderson JG, Shea MT, et al. (2000) The collaborative longitudinal personality disorders study: Baseline axis I/II and II/II diagnostic co-occurrence. Acta Psychiatrica Scandinavica 102(4): 256-264
21. Jovev M, Jackson HJ (2004) Early maladaptive schemas in personality disordered individuals. Journal of Personality Disorders 18(5): 467-478.

22. Ryder AG, Costa PT, Bagby RM (2007) Evaluation of the SCID-II personality disorder traits for DSM-IV: Coherence, discrimination, relations with general personality traits, and functional impairment. Journal of Personality Disorders 21(6): 626-637.

23. Ullrich S, Farrington DP, Coid JW (2007) Dimensions of DSM-IV personality disorders and life-success. Journal of Personality Disorders 21(6): 657-663.

24. Soeteman DI, Hakkaart van Roijen L, Verheul R, Busschbach JV (2008) The economic burden of personality disorders in mental health care. The Journal of Clinical Psychiatry 69(2): 259-265.

25. Osborn I (2015) Tormenting thoughts and secret ritual. International Journal For Research In Social Science And Humanities 1(1): 2-20.

26. Gosling SD (2008) Personality in non-human animals. Soc Pers Psychol Compass 2(2): 985-1001.

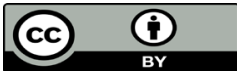

This work is licensed under Creative Commons Attribution 4.0 License

To Submit Your Article Click Here:

Submit Article

DOI: $10.32474 /$ JJNBD.2019.02.000142

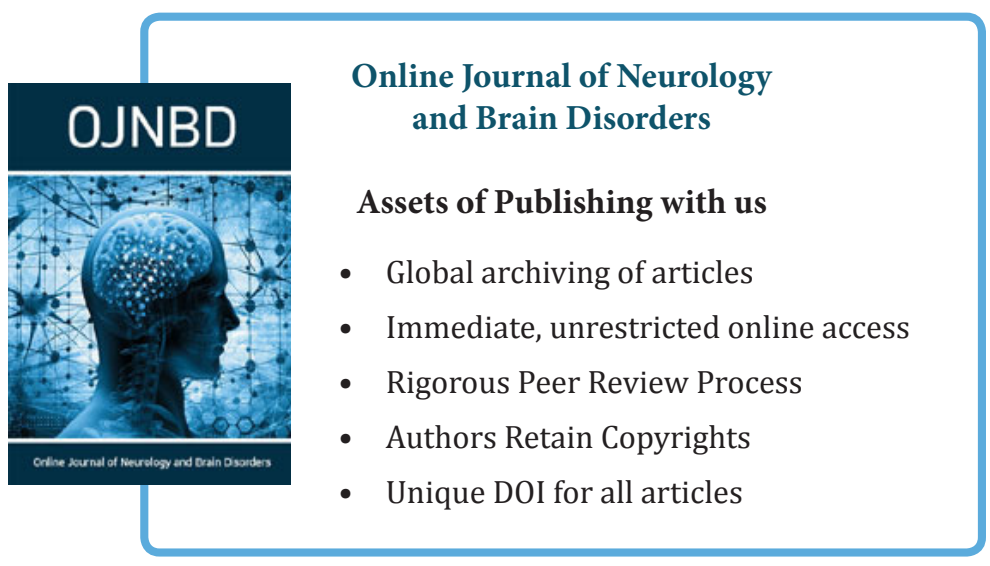

